\title{
DEFINITION OF LOCAL CLIMATE ZONES IN RELATION TO ENVI-MET AND SITE DATA IN THE CITY OF AL AIN, UAE
}

\author{
LINDITA BANDE, PRAJOWAL MANADHAR \& PRAHSANTH MARPU \\ United Arab Emirates University, UAE \\ Khalifa University, UAE
}

\begin{abstract}
The city of Al Ain, UAE has developed rapidly over the last two decades. Located in the south east of the United Arab Emirates, the origins of Al Ain were as an oasis. However, fast urban development has increased the number of built-up areas. Local climate zone (LCZ) classification provides a map of a city based on the similar properties of each zone, and WUDAPT is a network that facilitates its analysis. This approach allows developers to track the growth of the city. This study is based on satellite images and Google Earth Pro. High-definition satellite images are used to detect the specifics of each building morphology and district pattern. The new city map is then compared with the CFD models generated by ENVI-met. The models are based on site surveys and information taken from the authorities in the municipality of Al Ain, while the boundary conditions are based on information taken from local climate stations. Al Ain has a hot, arid climate with very dry, hot summers and the city is composed of desertified areas of red sand. To the east is a rocky mountain that affects the climate of the city. This study will focus on the spring and summer seasons due to the extreme changes in temperature. The outcome of this study is an analysis of the urban heat island effect (UHI). The aim is to detect problematic districts and to analyse their morphology. The widespread use of trees in the city improves the impact of the UHI, although the high speed of construction has produced dense, built-up areas. The LCZ and the results of ENVI-met simulations are used to define the levels of UHI in each zone analysed in this study.
\end{abstract}

Keywords: local climate zone, WUDAPT, heat island effect, ENVI-met, city mapping.

\section{INTRODUCTION}

Although most of the current population now lives in urban areas, we still have very little information about these areas, for example how they are built and how they function globally. The majority of the data that exist relate to the administrative regions that are often co-located with the built-up areas. Where spatial information is available, it focuses on distinguishing the urban impression, that is, the place the city resides. While this information has been shown to be helpful for some climate studies, detailed information is still missing at global, regional and even at urban levels [1]-[3].

In the last few decades, significant progress has been made towards urban climate modelling with regard to capturing the urban process at regional and urban scales. The link between landscape change and climate has been visualised in recent research on several urban cities, namely the World Urban Database and Portal Tool (WUDAPT). This is a global collaborative project dedicated to the acquisition, storage and dissemination of climaterelevant data on the physical geographies of cities worldwide.

The use of ENVI-met software allows the modelling the six different climate zones considered in this study. This tool has been extensively used among architects and urban planners. As several studies have shown, ENVI-met generates an overestimation of the mean radiant temperature during peak hours, due to the heat trapped within the canyon. In addition, if not properly modified, some layers of the soil can present a barrier to calculating the heat fluxes within the different layers of the soil. Another disadvantage of the ENVI-met 4.0 
software used in this study is the absence of anthropogenic heat generated by cars, which may have an impact of $0.53^{\circ}$ on the peak air temperature. However, if the models are created in detail, an estimation of the microclimate and the different strategies used can give reliable results [4]-[7].

Site measurements are a mandatory aspect of the validation of this study. In several cases, site measurements ensure that the models are close to the real conditions. The sensors used in the external conditions may experience failures over time, caused by overheating of the plates surrounding the sensors. The harsh climate of the region makes this process more complex, depending on the location of the installation. In several studies, networks of sensors around neighbourhoods such as Singapore and Basel have been used in the validation of simulation models. In this study, the sensors are installed only in one type of district [8]-[11].

\section{METHODOLOGY}

Our methodology is based on the process of this study. Initially, the city of Al Ain was selected due to the range of data that were available, its specific location within the country, the characteristic microclimate of the city, and the generally hot, arid conditions, in contrast to coastal cities with high humidity levels. Site measurements were carried out, and these were followed by simulations and modelling. The results from each tool are then compared and adjusted as per the specified method. The conclusions form points of reference for a more detailed study based on the current analysis [12]-[14].

\subsection{City analysis: selection of the districts}

Al Ain City is located close to the border of Oman and has a specific microclimate. Due to its location, deep in the desert, the city has a hot, arid climate. The oasis and the date farms around the city form green corridors of evapotranspiration and sources of humidity. Over the last two decades, the city has developed rapidly, and this development has given rise to the construction of districts with different types of buildings. In this study, the six districts examined are representative of most of the districts in the city.

District 1: This area is composed of villas with two or three floors. The spaces between buildings are within an average range. The internal streets have trees, and the road surface is paved. District 2: This is an area of closely spaced villas, and is another representative district mainly designed to accommodate expats. District 3: High-rise buildings represent the newest form of neighbourhood in the city. The need for accommodation for expats gave rise to the development of these neighbourhoods. The architecture of this area is similar to the residential areas of European cities. District 4: Mid-rise buildings represent part of the central zone of the city. These buildings are close to each other, giving a high density for this built-up area. District 5: Large villas are characteristic of this area; these are sizeable buildings, usually with two or three floors, with service areas around the units. The greenery around the building is much denser than in District 1, and the built-up area is much smaller. District 6: Industrial zones are those that contain production factories. In this city, these zones are distributed towards the east and south, on the border with Oman. Most of the factories are related to car repair and maintenance, but food is also processed here. The material of the façades is typically aluminium and the streets are mainly surfaced with asphalt. There are no trees around this zone. 


\subsection{Site measurements}

Site measurements were used for the validation of the CFD models. The information obtained from these measurements was used to validate the different software tools used in this research, such as ENVI-met, Fluent etc. The network of sensors used in this validation was installed in the most relevant areas. Each unit included an air temperature sensor, a relative humidity sensor and a wind speed sensor, and measurements were taken once per month. Several difficulties were expected during the process, such as high air temperatures, battery failures and sandstorms. The focus was on gathering a complete year of data without interruptions.

Zone A: This zone contains a high metallic shading structure. In the morning and evening hours, the pavement becomes overheated, making it difficult for users to walk and to adapt to the current conditions. Zone B: This zone has no shading devices; although palm trees were initially planned for this area, it is currently open, and every part of the court is exposed to unobstructed solar radiation. There is a stationary water feature to the side of the area. A fountain would be helpful in creating evaporative cooling, since the climate of the city is relatively dry. However, this is subject to further observation and site measurements. Zone $\mathrm{C}$ : This zone contains a high metallic shading structure and metallic plates on the side areas, and the metallic material causes the path to overheat. The main function of the side panels is to create a shaded, private path due to certain cultural requirements and a specific climate typology. Zone D1: This zone has no shading, although palm trees are planned and are currently partially planted. Zone D2: This area has no shading devices, and is a direct exit from the C6 building, where there is no buffer zone. All zones are shown in Table 1. Fig. 1 shows the location of one of the sensors.

\subsection{Modelling and simulations}

Two main softwares are used for the modelling: WUDAPT and ENVI-met.

\subsubsection{WUDAPT software}

In this study, we use Level 0 of the LCZ classification scheme. Level 0 data describe a city in terms of its constituent neighbourhood types using the LCZ scheme [3]. The types of LCZ describe urban landscapes based on their effect on the local air temperature; they are also associated with values relating to urban form and function variables that may be used in some types of urban climate models. The steps for gathering Level 0 data are described by Bechtel et al. [3].

An individual who knows the city (an urban expert) defines a domain that encloses the urban area and identifies parts of the natural and urban landscape that represent LCZ types. These training areas are created as polygons using Google Earth and are then imported into SAGA software.

Landsat 8 data (http://landsat.usgs.gov/landsat8.php) for the urban domain are then extracted and imported into the SAGA software, which has GIS and remote sensing capabilities. The LCZ training areas are then used to classify the entire urban domain into neighbourhood types, using a random forest classification scheme. The expert examines the map and adds to (or modifies) the LCZ training areas to account for misclassifications and repeats the process until satisfied. The accuracy of the final product is evaluated by comparing the predicted and observed LCZ type for selected areas.

The Weather Research and Forecasting Model (WRF) is a next-generation mesoscale numerical weather prediction system that is designed for both atmospheric research and 
Table 1: Site location of the sensor units.

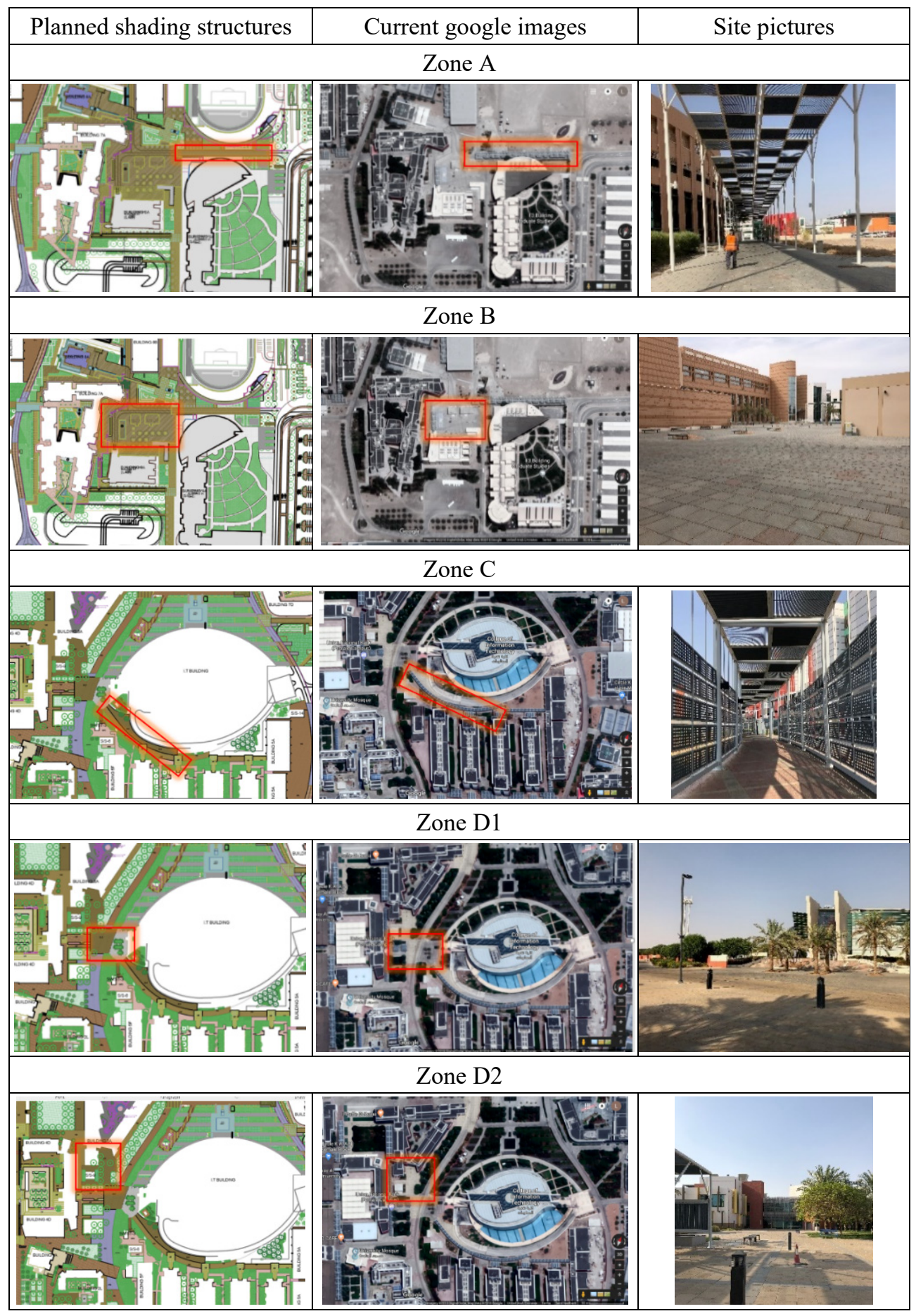



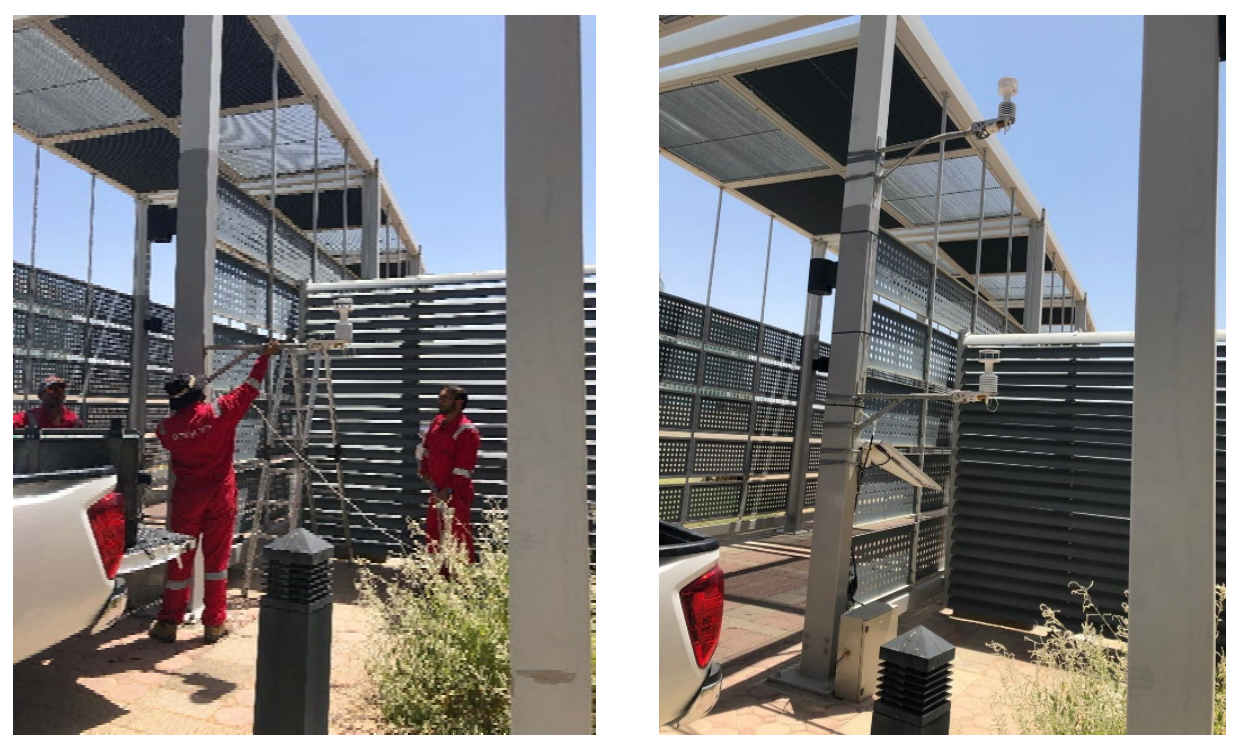

Figure 1: Site images of the installed sensor unit.

operational forecasting applications. It consists of two dynamical cores, a data assimilation system and a software architecture supporting parallel computation and system extensibility. The model can process a wide range of meteorological applications across scales from tens of metres to thousands of kilometres. WRF can produce simulations based on actual atmospheric conditions (i.e. from observations and analyses) or idealised conditions. It offers operational forecasting via a flexible and computationally efficient platform, while reflecting recent advances in physics, numerical and data assimilation contributed by developers from the wider research community. The operational WRF model is used to obtain simulations of various weather parameters, one of which is the land surface temperature (LST). We use LSTs obtained over a grid of size $16 \mathrm{~km}^{2}$. We compare our measured air temperatures against the simulated LSTs to show that the air temperature measurements from our sensors follow both the rising and the falling trends in LSTs. We can see from a plot of LST vs. temperature that the air temperature is above the LST in the morning and evening, and vice versa during the afternoon (Fig. 2).

\subsubsection{ENVI-met simulations}

Table 2 shows the ENVI-met models. The six selected districts were built with version 4.0. The walls and other surface materials were modified from the original ENVI-met template. The 3D shown in the table has a telescoping factor greater than $20 \mathrm{~m}$, meaning that the use of $3 \mathrm{D}$ in the images is not realistic. This change was made in order to save time in the simulation. In this version of the software, the simulation runs for $24 \mathrm{~h}$. The study was carried out in summer, and the simulation was run for 18th June, corresponding to the date of the site measurements. The model was run only for District 3, due to time limitations, and the size of the model was limited to $100 \times 100$, also due to the time requirements of the software. Since this was a CFD tool, the processing time required by the software was longer than for other tools. The results were then compared with the LCZ and modified as per the proposed method [15]-[17]. 
6- Open Low-rise

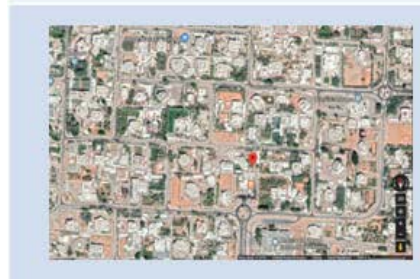

2- Compact mid-rise

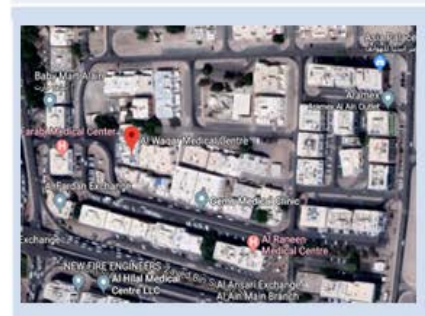

\section{A-Dense Trees}

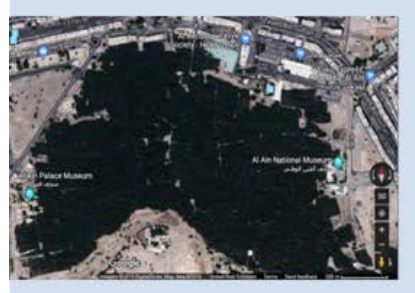

\section{E- Bare rock or paved}

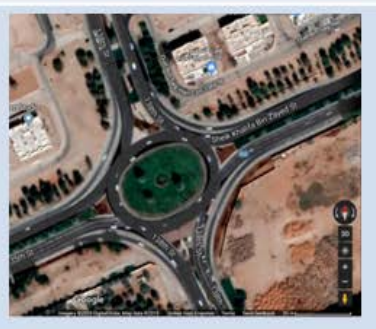

3- Compact Low-rise

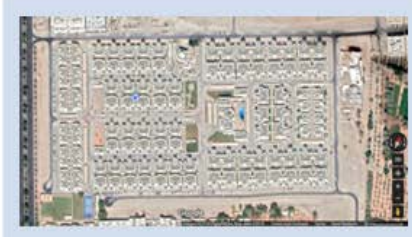

9- Sparsely built

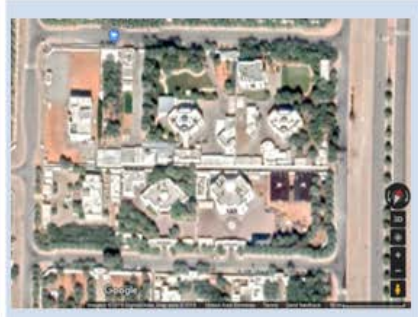

B-Scattered Trees

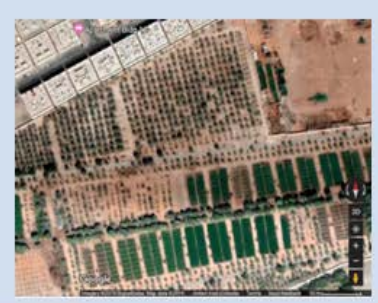

\section{F-Base soil or sand}

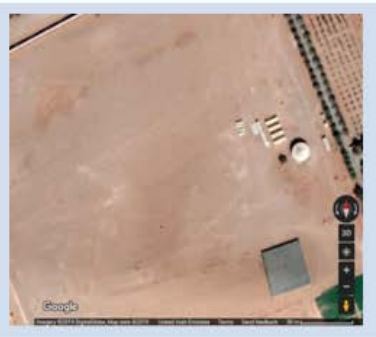

1- Compact High-rise

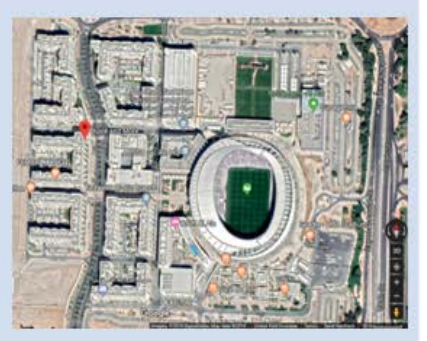

10- Heavy Industry

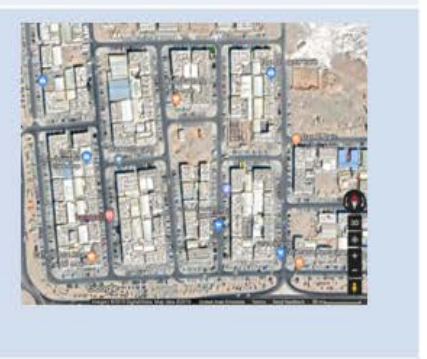

C- Bush, scrub

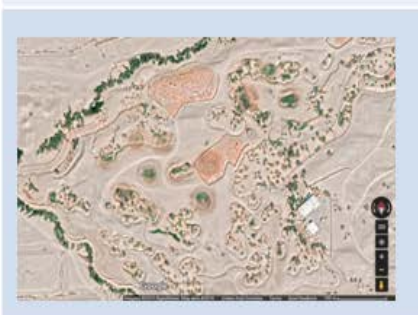

G- Water

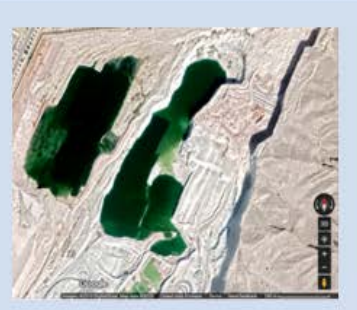

Figure 2: Twelve different LCZ samples (the class label in this figure is similar to the original LCZ class). 
Table 2: ENVI-met simulations.

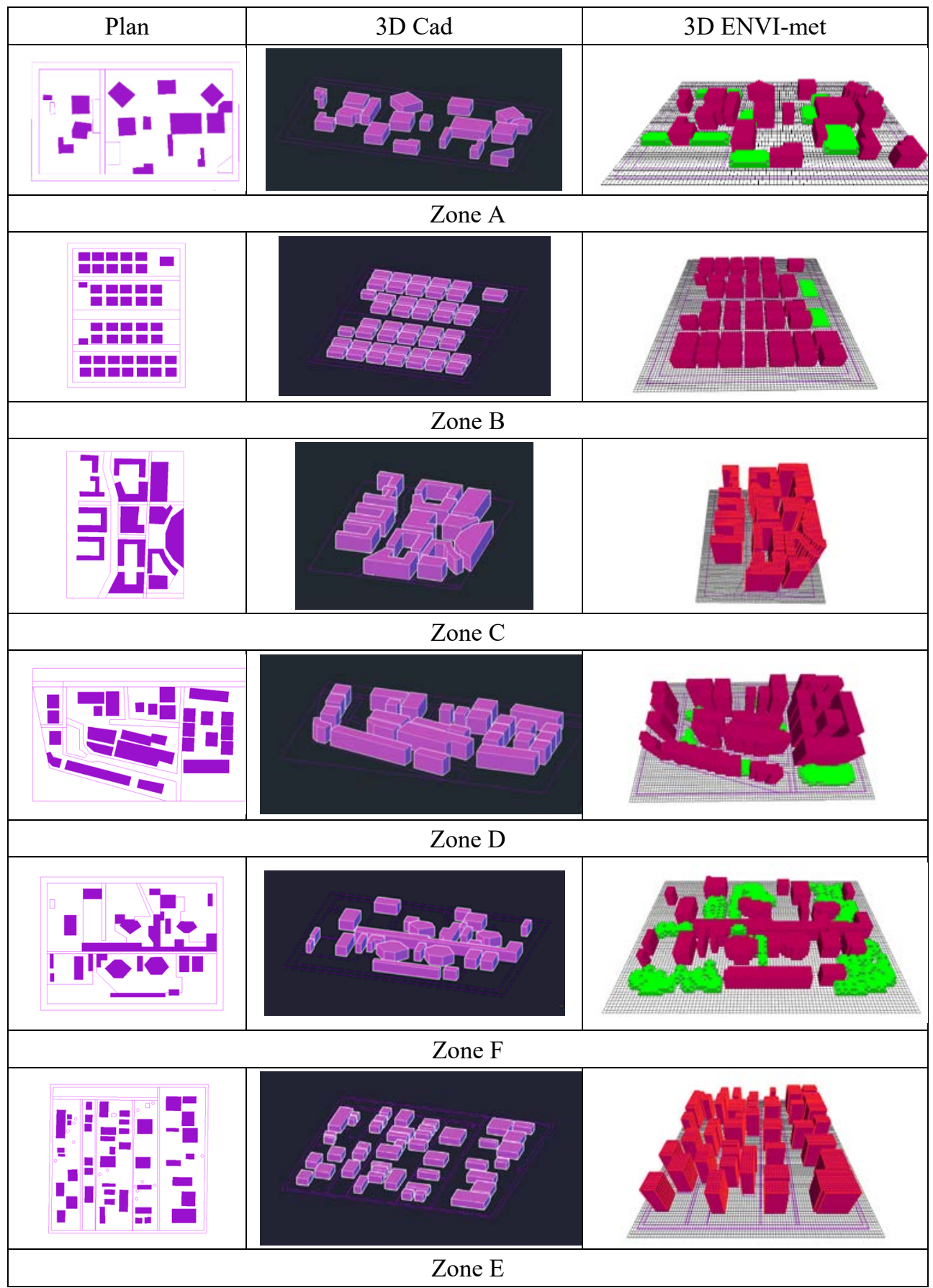




\subsection{Results}

The results are shown in two sections: the WUDAPT results and the ENVI-met results.

\subsubsection{WUDAPT results}

Data: We make use of Landsat satellite data for LCZ classification. Landsat 8's Operational Land Imager (OLI) uses improved sensors compared to previous versions. The main instrument includes the Thematic Mapper (TM), the Enhanced Thematic Mapper Plus $(\mathrm{ETM}+)$, which provides data in eight bands with a spatial resolution of $30 \mathrm{~m}$ and a panchromatic band with a resolution of $15 \mathrm{~m}$, and a thermal infrared sensor with a spatial resolution of $100 \mathrm{~m}$.

Through a careful study of the heights of the buildings, the land use and land cover areas, the $\mathrm{Al}$ Ain region can be classified into six types of buildings and six land cover classes, i.e. a total of $12 \mathrm{LCZ}$ classes, as shown in Fig. 1. The LCZ classification task is performed (as shown in Fig. 3) using SAGA software on Landsat images (shown in Fig. 2) after the careful selection of a minimum of three samples of each class. Fig. 4 shows the outcome of the LCZ for the region of the Al Ain City.

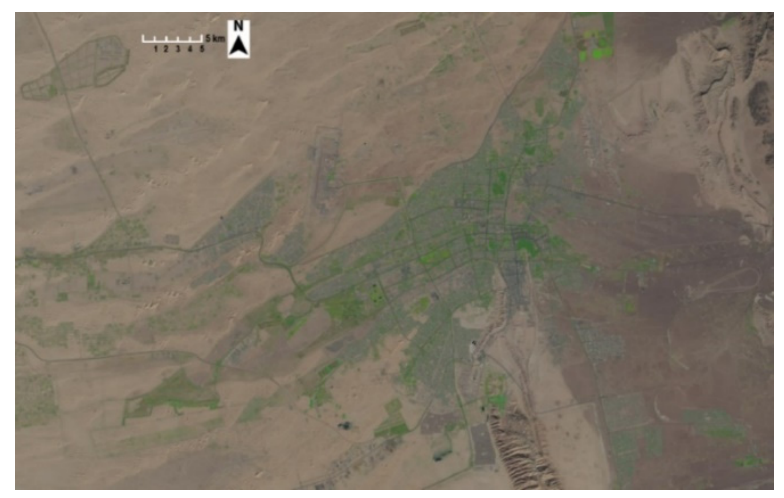

Figure 3: Landsat images for the Al-Ain region.

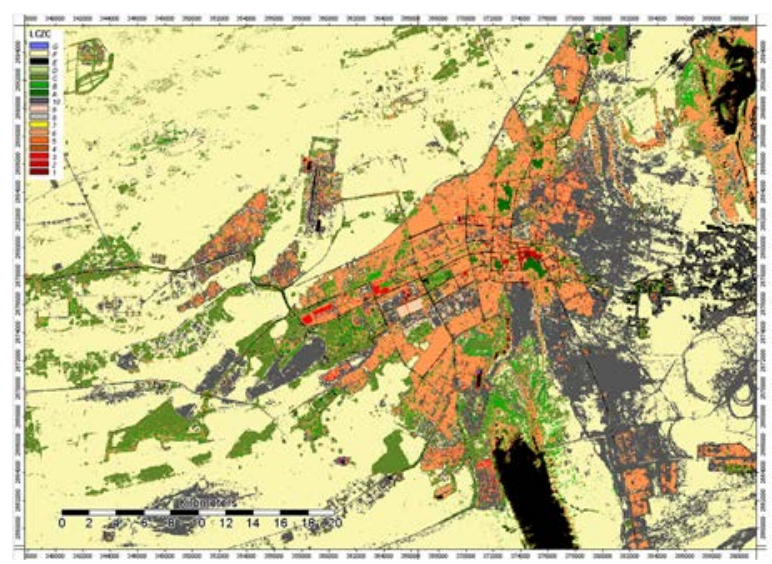

Figure 4: LCZ classification results for the Al Ain region. 


\subsubsection{ENVI-met results}

The ENVI-met results show the different air temperatures at a height of $5 \mathrm{~m}$. Figs 5 and 6 show the results for $1.00 \mathrm{pm}$ and $5.00 \mathrm{pm}$. The results for a $24 \mathrm{~h}$ period are compared with the results from LST in Figs 7, 8 and 9. Since a discrepancy is obvious between the simulation results and the measurements of the sensors, we use a fitting model. The model developed to fit the ENVI-met simulation is $y=m . x+c$, where $m=1.198$ and $c=-6.941$. As shown in the figures above, the graphs follow the same trend after modification of the ENVI-met results.
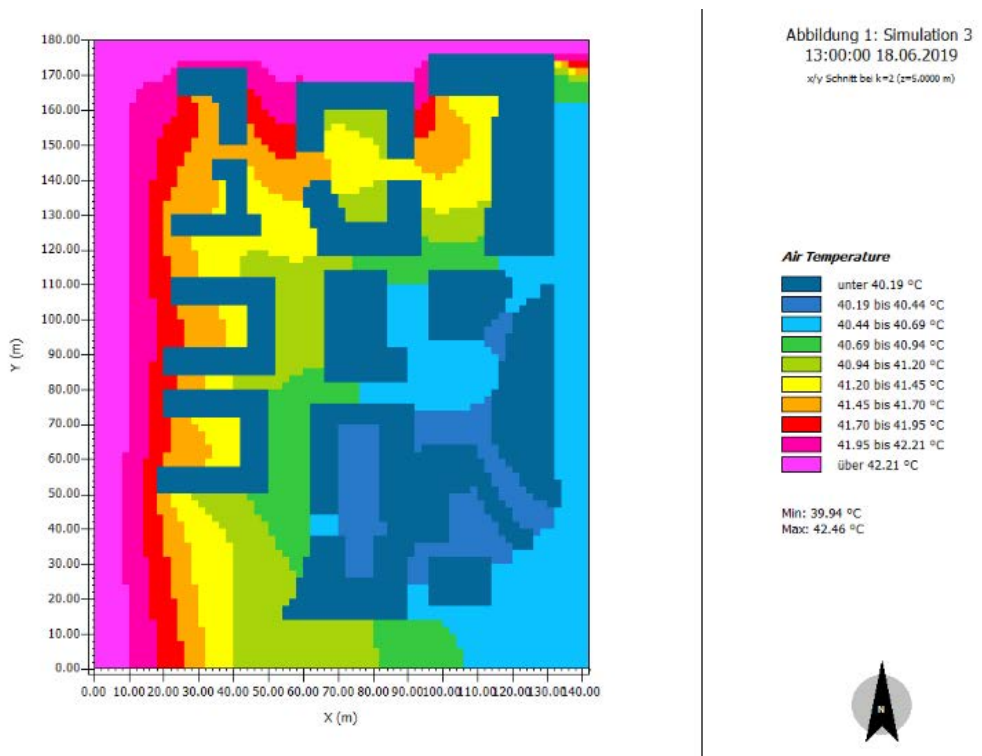

Figure 5: ENVI-met results for $1.00 \mathrm{pm}$.
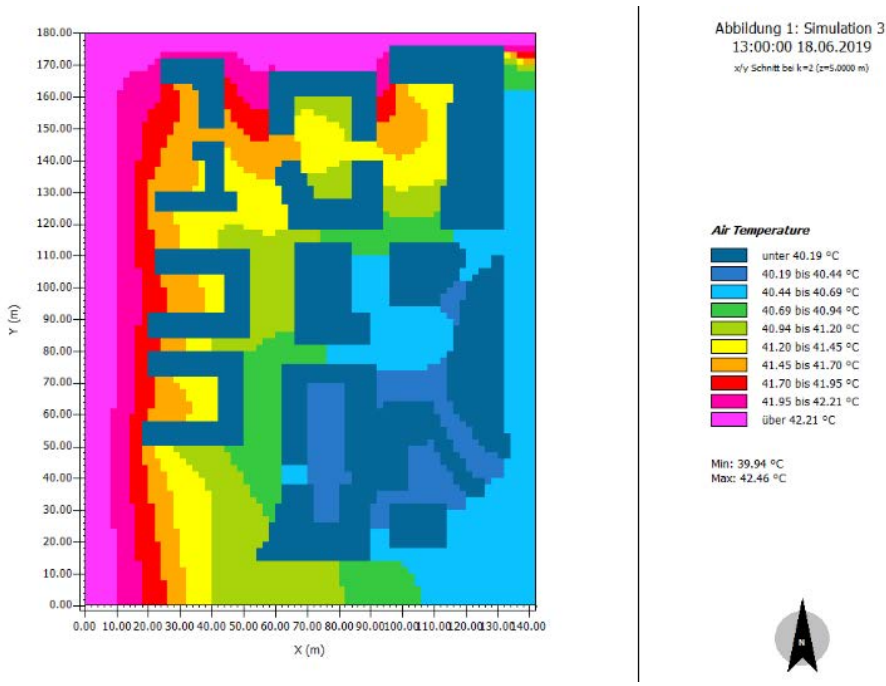

Figure 6: ENVI-met results for $5.00 \mathrm{pm}$. 


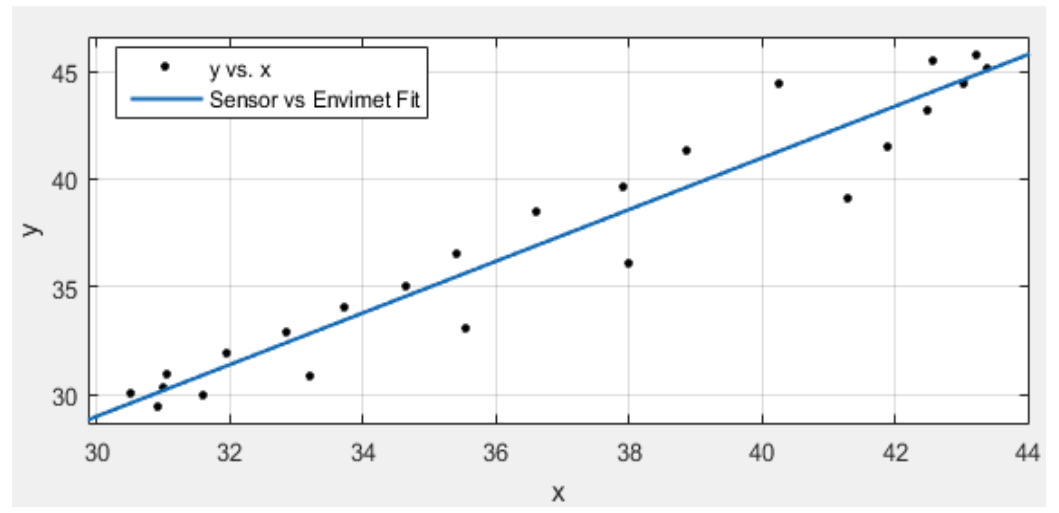

Figure 7: Sensor vs. ENVI-met fi.

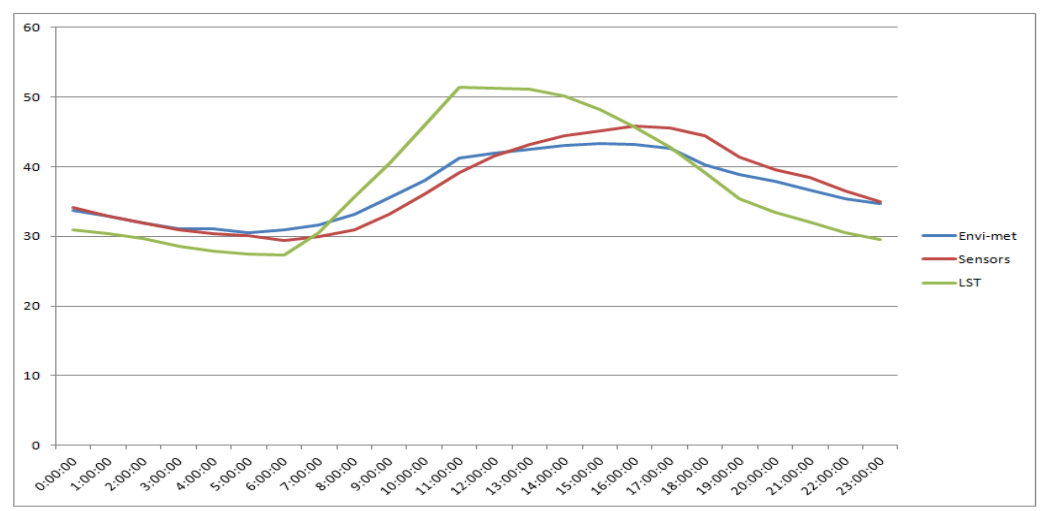

Figure 8: Comparison between ENVI-met simulation results, temperature measured by sensors and LST modelled using WRF.

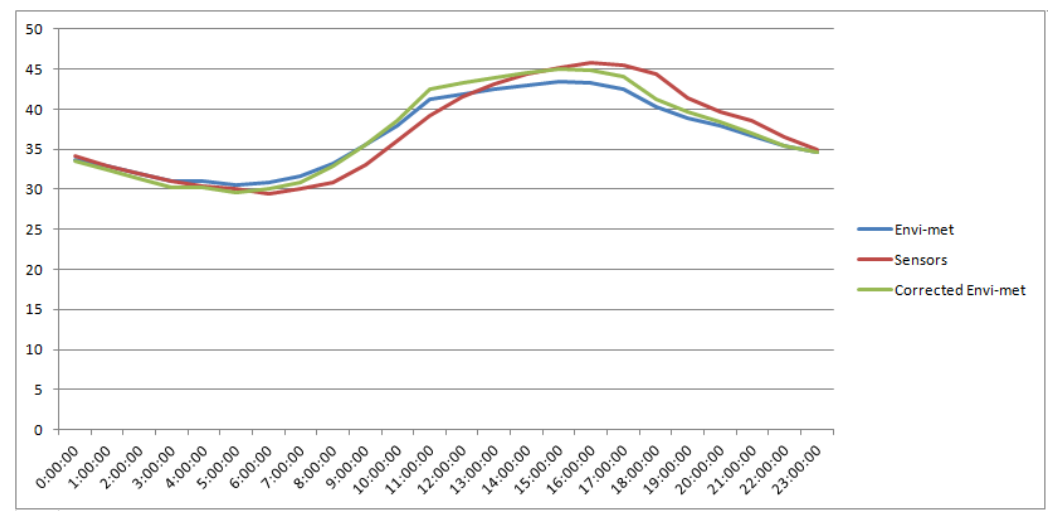

Figure 9: Corrected ENVI-met results with RMSE of 1.5. 


\section{CONCLUSIONS AND FUTURE WORK}

The results of this study show that the definitions of the climate zones are in alignment with the results from ENVI-met, and the site measurements follow the same trend. Mapping the city is valuable in order to understand the distribution of built-up areas and the expansion of the city. Climate change is also related to the built-up areas. These records allow us to understand which zones need further intervention in terms of "cooling down" the city, as an immediate task. In this study, an ENVI-met simulation was carried out for only one district; however, in future work, simulations will be run for all districts. This will help us understand the compatibility of the ENVI-met results with the different district typologies.

\section{ACKNOWLEDGEMENT}

This study would have not been possible without support and the start-up funding, fund code 31N379, from AE Department, COE, United Arab Emirates University.

\section{REFERENCES}

[1] Stewart, I.D. \& Oke, T.R., Local climate zones for urban temperature studies. Bulletin of the American Meteorological Society, 93(12), pp. 1879-1900, 2012.

[2] Mills, G. et al., An introduction to the WUDAPT project. Proceedings of the 9th International Conference of Urban Climate jointly with 12th Symposium on the Urban Environment, 2015.

[3] Bechtel, B. et al., Mapping local climate zones for a worldwide database of the form and function of cities. ISPRS International Journal of Geo-Information, 4(1), pp. 199219, 2015.

[4] Bande, L., Heat island mitigation strategies, with focus on the urban shading devices: The case study of Abu Dhabi Main Island, United Arab Emirates. Doctoral dissertation, 2017.

[5] Bande, L., Cabrera, A.G., Afshari, A. \& Martin, M., Evaluation of smart shading structures in mitigating urban heat island in a district of a hot arid climate city (Abu Dhabi), 2015.

[6] Thomas, A.E., \& Elizabeth, A., Sustainable landscapes for residential neighborhoods in Dubai: An analysis of the relationship between ambient temperature and water requirements of landscape. Masters thesis, The British University in Dubai, 2013.

[7] envimet, Home. www.envi-met.com.

[8] Bueno, B., Roth, M., Norford, L. \& Li, R., Computationally efficient prediction of canopy level urban air temperature at the neighbourhood scale. Urban Climate, 9, pp. 35-53, 2014.

[9] Oke, T., NOTE The Thirteenth Session of the Commission for Instruments and Methods of Observation (CIMO) recognized the need to include in the WMO Guide to Instruments and Methods of Observation, WMO-No.8 (CIMO Guide): A New Chapter on Urban Observations.

[10] Toppi, T., Zangheri, P., \& Paolini, R., Simplified Method for Modification of Weather Data File for Energy Simulations within Urban Areas, 2009.

[11] Yuan, C. \& Chen, L., Mitigating urban heat island effects in high-density cities based on sky view factor and urban morphological understanding: A study of Hong Kong. Architectural Science Review, 54(4), pp. 305-315, 2011.

[12] Radhi, H., Evaluating the potential impact of global warming on the UAE residential buildings: A contribution to reduce the $\mathrm{CO}_{2}$ emissions. Building and Environment, 44(12), pp. 2451-2462, 2009. 
[13] Carboun, Middle East Sustainable Cities, Passive Cooling: Responding to Electricity Demand in the UAE. www.carboun.com/sustainable-design/passive-coolingresponding-to-uae's-soaring-electricity-demand/.

[14] Ministry of Environment and Water of UAE, UAE State of Green Economy 2014, 2014.

[15] Roth, M. \& Lim, V.H., Evaluation of canopy-layer air and mean radiant temperature simulations by a microclimate model over a tropical residential neighbourhood. Building and Environment, 112, pp. 177-189, 2017.

[16] Ozkeresteci, I., Crewe, K. \& Bruse, M., Cartographic renaissance. Hosted by The International Cartographic Association (ICA), 2003.

[17] Huttner, S. \& Bruse, M., Numerical modeling of the urban climate: A preview on ENVI-MET 4.0, 2009. 